\title{
Cardiovascular protection and blood pressure reduction: a meta-analysis
}

\author{
Jan A Staessen, Ji-Guang Wang, Lutgarde Thijs
}

\section{Summary}

Background Whether antihypertensive drugs offer cardiovascular protection beyond blood pressure lowering has not been established. We aimed to investigate whether pharmacological properties of antihypertensive drugs or reduction of systolic pressure accounted for cardiovascular outcome in hypertensive or high-risk patients.

Methods In a meta-analysis we extracted summary statistics from published reports, and calculated pooled odds ratios for experimental versus reference treatment. We correlated across-trials odd ratios for differences in systolic pressure between groups.

Findings We analysed nine randomised trials comparing treatments in 62605 hypertensive patients. Compared with old drugs (diuretics and $\beta$-blockers), calcium-channel blockers and angiotensin converting-enzyme inhibitors offered similar overall cardiovascular protection, but calciumchannel blockers provided more reduction in the risk of stroke $(13 \cdot 5 \%, 95 \% \mathrm{Cl} 1 \cdot 3-24 \cdot 2, \mathrm{p}=0 \cdot 03)$ and less reduction in the risk of myocardial infarction $(19.2 \%, 3.5-37.3$, $\mathrm{p}=0 \cdot 01$ ). Heterogeneity was significant between trials because of high risk of cardiovascular events on doxazosin in one trial, and high risk of stroke on captopril in another; but systolic pressure differed between groups in these two trials by $2-3 \mathrm{~mm} \mathrm{Hg}$. Similar systolic differences occurred in a trial of diltiazem versus old drugs, and in three trials of converting-enzyme inhibitor against placebo in high-risk patients. Meta-regression across 27 trials (136 124 patients) showed that odds ratios could be explained by achieved differences in systolic pressure.

Interpretation Our findings emphasise that blood pressure control is important. All antihypertensive drugs have similar long-term efficacy and safety. Calcium-channel blockers might be especially effective in stroke prevention. We did not find that converting-enzyme inhibitors or $\alpha$-blockers affect cardiovascular prognosis beyond their antihypertensive effects.

Lancet 2001; 358: 1305-15

\section{Studiecoördinatiecentrum, Hypertensie en Cardiovasculaire Revalidatie Eenheid, Departement Moleculair en Cardiovasculair Onderzoek, Katholieke Universiteit Leuven, Leuven, Belgium (J A Staessen MD, L Thijs MSc, J G Wang MD)}

Correspondence to: Dr Jan A Staessen, Studiecoördinatiecentrum, Laboratorium Hypertensie, Campus Gasthuisberg, Gebouw Onderwijs en Navorsing, Herestraat 49, B-3000 Leuven, Belgium (e-mail: jan.staessen@med.kuleuven.ac.be)

\section{Introduction}

Lifetime risk of hypertension is about $20 \%$. Several trials have been done to find the best possible protection against the cardiovascular complications of this widespread condition. Various drugs were tested to see whether their mode of action or ancillary properties could offer benefit beyond their effect of lowering blood pressure. ${ }^{1-16}$ In normotensive and hypertensive high-risk patients in the HOPE study, ${ }^{7}$ the angiotensin-converting enzyme (ACE) inhibitor ramipril significantly reduced rates of death, stroke, and myocardial infarction compared with placebo. In hypertensive patients enrolled in ALLHAT, ${ }^{10}$ fewer cardiovascular events happened during treatment with chlorthalidone than with the $\alpha$-blocker doxazosin. However, in both studies, ${ }^{7,10}$ systolic pressure was 2-3 $\mathrm{mm} \mathrm{Hg}$ lower in the group with the best outcome, which could have been sufficient to explain the results. ${ }^{17-19}$ Two quantitative overviews ${ }^{20,21}$ reached opposite conclusions with respect to cardiovascular protection of calcium-channel blockers compared with diuretics or $\beta$ blockers. However, neither of these overviews $s^{20,21}$ specifically assessed blood pressure differences between randomised groups in relation to heterogeneity among trials, or included $\alpha$-blockers in the group of newer drugs.

We investigated whether pharmacological properties of antihypertensive drugs or blood pressure reduction explained cardiovascular outcome. We focused on systolic pressure because, in middle-aged and older patients, systolic pressure is a better predictor of cardiovascular risk than diastolic pressure, ${ }^{22}$ and systolic pressure can be measured more reliably than diastolic pressure. ${ }^{23}$ First, we assessed whether differences in achieved systolic pressure between randomised groups led to heterogeneity among outcome trials of old versus new classes of antihypertensive drugs. Second, we used metaregression to measure to what extent blood pressure reduction accounts for results of outcome trials.

\section{Methods}

Trials

We searched for outcome trials that tested drugs to lower blood pressure in normotensive or hypertensive patients who did not have overt heart failure at enrolment. Other inclusion criteria were a randomised controlled design, publication in a peer-reviewed journal, inclusion of patients with hypertension, assessment of blood pressure and cardiovascular events, follow-up of 2 years or longer, and sample size of 100 or more. Outcome trials of drugs to lower blood pressure were identified from previous overviews $\mathbf{s}^{17,18,20,21,24,25}$ and from a Medline search for trials with expected publication date before $2001 .^{25}$

For the first part of our review, we selected outcome trials in hypertensive patients that compared old classes of antihypertensive agents, such as diuretics or $\beta$-blockers, with new agents such as calcium-channel blockers, ACE inhibitors, or $\alpha$-blockers. We identified 11 such studies. ${ }^{1-6,8-10,14,16}$ We excluded one trial ${ }^{1}$ because randomisation was not between old and new drugs but between special intervention and usual care, and a second study $^{2}$ because cardiovascular outcome data were 


\begin{tabular}{|c|c|c|c|c|c|c|c|c|c|}
\hline \multirow[t]{2}{*}{ Characteristic } & \multicolumn{9}{|l|}{ Trials } \\
\hline & UKPDS $^{16,27 *}$ & STOP $^{6}$ & CAPPP $^{4}$ & NORDIL $^{9}$ & INSIGHT ${ }^{8}$ & ALLHAT $^{10}$ & MIDAS $^{3}$ & $\mathrm{NICS}^{5}$ & VHAS $^{63} \dagger$ \\
\hline Masking type & Open & Open & Open & Open & Double & Double & Double & Double & Open \\
\hline Number of patients & 1148 & 6614 & 10985 & 10881 & 6321 & 24335 & 883 & 414 & 1414 \\
\hline \multicolumn{10}{|l|}{ Treatment } \\
\hline Reference & $\begin{array}{l}\text { Atenolol } \\
<180 / 105\end{array}$ & $\begin{array}{l}\text { HCTZ/A or } \\
\beta \text {-blockers }\end{array}$ & $\begin{array}{l}\text { Diuretic or } \\
\beta \text {-blockers }\end{array}$ & $\begin{array}{l}\text { Thiazide or } \\
\beta \text {-blockers }\end{array}$ & HCTZ/A & $\begin{array}{l}\text { Chlorthali- } \\
\text { done }\end{array}$ & $\mathrm{HCTZ}$ & $\begin{array}{l}\text { Trichlorme } \\
\text { thiazide }\end{array}$ & $\begin{array}{l}\text { Chlorthali- } \\
\text { done }\end{array}$ \\
\hline Experimental & $\begin{array}{l}\text { Captopril } \\
<150 / 85\end{array}$ & $\begin{array}{l}\text { ACEls } \\
\text { DHPS }\end{array}$ & Captopril & $\begin{array}{l}\text { Diltiazem } \\
\text { (SR) }\end{array}$ & $\begin{array}{l}\text { Nifedipine } \\
\text { (GITS) }\end{array}$ & Doxazosin & Isradipine & $\begin{array}{l}\text { Nicardipine } \\
\text { (SR) }\end{array}$ & $\begin{array}{l}\text { Verapamil } \\
\text { (SR) }\end{array}$ \\
\hline $\begin{array}{l}\text { Age (mean [SD], years) } \\
\text { Mean systolic/diastolic blood } \\
\text { pressure (mm Hg) }\end{array}$ & $56(8)$ & $76(\cdot \cdot)$ & $53(8)$ & $60(7)$ & $65(7)$ & $67(8)$ & $59(9)$ & $70(7)$ & $53(7)$ \\
\hline At entry & $160 / 94$ & $194 / 98$ & $161 / 99$ & $173 / 106$ & $167 / 96$ & $145 / 83 \ddagger$ & $150 / 97$ & $172 / 94$ & $169 / 102$ \\
\hline Difference during follow-up§ & $-1 /-1$ & $-0 \cdot 3 /+0 \cdot 5$ & $-3 /-1$ & $-3 \cdot 1 /+0 \cdot 2$ & $\sim 0 / \sim 0$ & $-2 /+1$ & $-3 \cdot 5 / \sim 0$ & $-0 \cdot 7 /-1 \cdot 2$ & $-1 \cdot 0 /+0 \cdot 4$ \\
\hline \multicolumn{10}{|l|}{ Proportion of patients (\%) } \\
\hline Women & 45 & 67 & 47 & 51 & 54 & 47 & 22 & 67 & 51 \\
\hline Cardiovascular complications & .. & $\sim 20$ & 4 & $\sim 8$ & $\sim 20$ & 45 & $\sim 4$ & $\sim 28$ & 5 \\
\hline Diabetes mellitus & 100 & 11 & 5 & 7 & 21 & 36 &.. & .. & $4 \|$ \\
\hline \multicolumn{10}{|l|}{ Follow-up (years) } \\
\hline Median & $8 \cdot 4$ &.$\cdot$ &.. &.. &.. & $3 \cdot 3$ & $3 \cdot 0$ & $4 \cdot 3$ & $2 \cdot 0$ \\
\hline Mean &.. & $5 \cdot 0$ & $6 \cdot 1$ & 4.5 & 3.5 &.. &.. &.. &.. \\
\hline
\end{tabular}

ACEls=angiotensin-converting enzyme inhibitors; DHPs=dihydropyridine calcium-channel blockers (felodipine or isradipine); GITS=gastro-intestinal therapeutic system; $\mathrm{HCTZ=hydrochlorothiazide;} \mathrm{HCTZ/A=hydrochlorothiazide} \mathrm{plus} \mathrm{amiloride;} \mathrm{SR=sustained} \mathrm{release.} \mathrm{Acronyms} \mathrm{of} \mathrm{trials} \mathrm{are} \mathrm{explained} \mathrm{in} \mathrm{the} \mathrm{appendix.} \mathrm{*UKPDS} \mathrm{compared}$ captopril with atenolol and tested two levels of control of systolic/diastolic blood pressure. tIn VHAS, study drug was given in a double-blind fashion during the initial 6 months and thereafter in an open way. $\ddagger 90 \%$ of ALLHAT patients had blood pressure measured at entry while on antihypertensive treatment. $\S$ Negative values indicate tighter blood pressure control on old drug classes. ||Patients on antidiabetic drug treatment.

\section{Table 1: Characteristics of trials in hypertension comparing different active treatments}

published only in aggregate form. In our analysis, we combined three small trials ${ }^{3,5,14}$ that tested a calciumchannel blocker against a thiazide; in these trials less than 40 cardiovascular events occurred in 414 Japanese patients followed up for 5 years, ${ }^{5}$ or less than one event per 1000 patient-years. ${ }^{3,14}$

To study the relation between odds ratios of experimental versus reference treatment, and the corresponding baseline-corrected blood pressure differences, we included the nine trials in hypertensive patients that we selected for the first part of our overview, ${ }^{3-6,8-10,14,16}$ two reports comparing tight with relaxed blood pressure control, ${ }^{26,27} 11$ older studies in

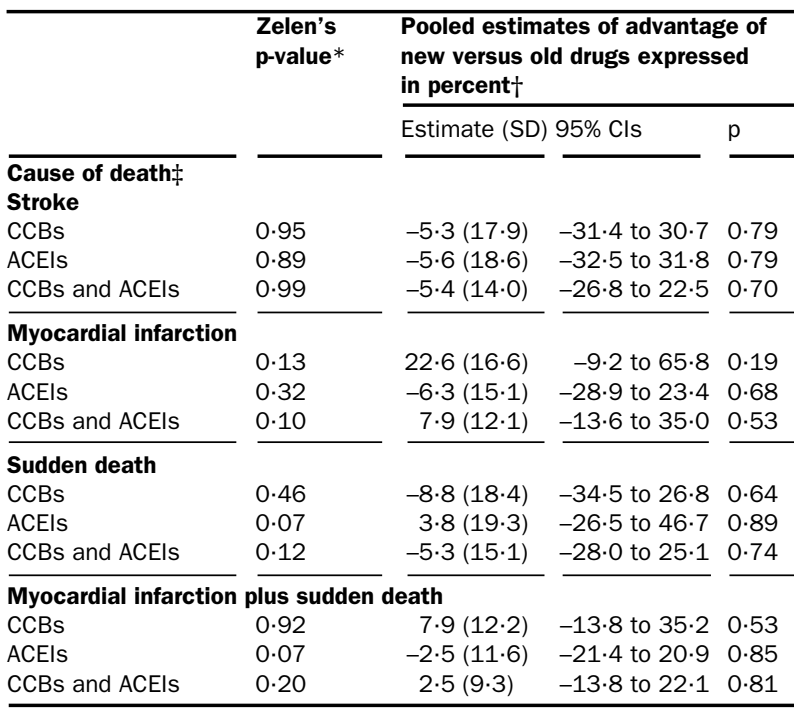

ACEls=angiotensin-converting enzyme inhibitors; $\mathrm{CCBs}=$ calcium-channel blockers. *The hypothesis of heterogeneity across the reviewed trials was rejected for all fatal outcomes. †Negative values indicate better outcome on rejected for all fatal outcomes. †Negative values indicate better outcome
the new drugs. ¥The reviewed trials are those listed in table 1 with the exception of ALLHAT, because cardiovascular mortality was unavailable from the published report. ${ }^{10}$ Cause-specific cardiovascular mortality was also not reported for MIDAS, ${ }^{3}$ NICS, ${ }^{5}$ and VHAS.

Table 2: Pooled estimates of advantage of new versus old antihypertensive drugs with respect to cause-specific mortality patients with systolic or diastolic hypertension comparing active treatment with no treatment ${ }^{28,29}$ or with placebo, ${ }^{30-38}$ three placebo-controlled studies in isolated systolic hypertension, ${ }^{39-41}$ and three placebo-controlled trials of ACE inhibitors in normotensive and hypertensive patients at high cardiovascular risk..$^{7,12,15}$ Among these 27 studies, two had a single-blind design with alternate allocation of consecutive patients to placebo or active treatment. ${ }^{34,41} \mathrm{We}$ excluded from our metaregression seven small trials in hypertension, ${ }^{42-48}$ which (in keeping with our exclusion criteria) accumulated fewer than 100 patients $^{46-48}$ or less than 2 years of follow-up, ${ }^{43,45}$ or did not provide information on systolic pressure ${ }^{44}$ or cardiovascular events. ${ }^{42}$ Because blood pressure, in particular systolic pressure, ${ }^{49}$ was not reported, we also excluded the HDFP study ${ }^{49}$ and two placebo-controlled trials on progression of atherosclerotic disease under treatment with quinapril ${ }^{11}$ or amlodipine. ${ }^{13}$ Because of similarity in design and few events we combined four small trials published in 1980 or before, ${ }^{29,36-38}$ and two placebo-controlled trials on progression of atherosclerosis with use of ACE inhibitors. ${ }^{12,15}$

We did not include trials that compared old with old drugs (ie, $\beta$-blockers with diuretics) ${ }^{50-52}$ or new with new compounds (ie, ACE inhibitors with calcium-channel blockers), ${ }^{53,54}$ because we could pool only few studies in outcome analysis, and because in metaregression analysis it was clinically difficult to define what was the reference treatment for calculation of odds ratios.

\section{Outcomes}

We based our analysis on the summary statistics published in 37 reports $^{3-10,12,14-16,26-41,55-63}$ on the 27 selected trials. Apart from fatal combined with non-fatal events in the EWPHE trial, ${ }^{30,55}$ all outcome results were reported on the basis of an intention-to-treat principle. EWPHE was one of the first intervention studies on treatment of hypertension and was planned in 1971. Patients who were randomised and who left the double-blind part of the study were followed up until July 1, 1984, but only date and cause of death were recorded. 


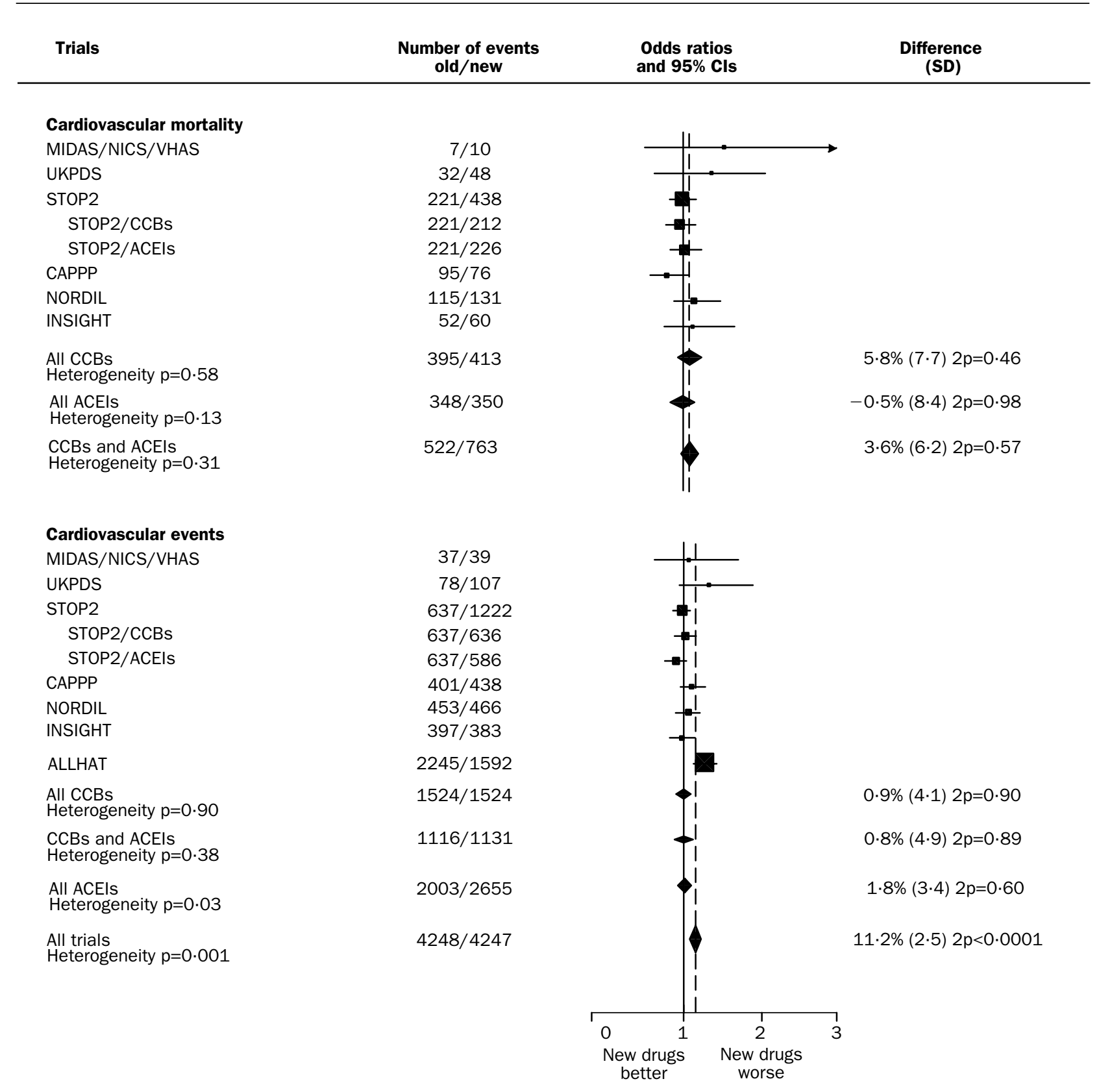

Figure 1: Effects of antihypertensive treatment on cardiovascular mortality and all cardiovascular events in trials comparing old with new drugs

Solid squares=treatment-to-control odds ratios in trials and have a size proportional to number of events. $95 \% \mathrm{Cl}$ for individual trials are denoted by lines and those for pooled odds ratios by diamonds. Acronyms and references of trials are in the appendix.

For comparison between old and new drugs, we extracted from nine reports ${ }^{3-6,8-10,14,16}$ the number of deaths from myocardial infarction, including and excluding sudden death, stroke, and all cardiovascular causes. Additionally, we noted the number of cardiovascular events, fatal and non-fatal strokes excluding transient ischaemic attacks, fatal and non-fatal myocardial infarctions, and fatal and non-fatal cases of congestive heart failure. For metaregression, we used only those events that could be consistently extracted from published reports ${ }^{3-10,12,14-16,26-41,55-63}$ on the 27 trials.

We had to accept the definitions of events used by the study investigators. In seven trials, ${ }^{4,6,7,9,15,26,31}$ the term all cardiovascular events refers to the primary composite endpoint. In Syst-Eur ${ }^{40,59,60}$ and Syst-China ${ }^{41,61}$ trials we used individual records of patients and the published definition of all cardiovascular events. For the other studies, we summed major cardiovascular events. Since more than one event might have happened to an individual, this approach is likely to have resulted in slight overestimation of the total number of patients with cardiovascular complications.

\section{Statistical analyses}

We assessed the relative benefit of experimental versus reference treatment from odds ratios in stratified $2 \times 2$ contingency tables. ${ }^{17,18}$ In every trial, the reference group was patients who were left untreated ${ }^{28,29}$ or allocated placebo, ${ }^{7,12,30-41}$ or patients randomly assigned old classes of drugs $^{3-6,8-10,14,16}$ or a treatment strategy leading to poor blood pressure control..$^{26,27}$

We used StatXact for Windows (version 4.0), to check homogeneity of odds ratios by Zelen's test, and to calculate exact $95 \%$ CIs. To enable comparisons with other overviews, ${ }^{17,18,20,21,24}$ we also derived SDs of pooled odds ratios by analogy with the asymptotic approach by division 
of the exact logarithmically transformed $95 \%$ CI by $(2 \times 1 \cdot 96)$. All pvalues are for two-sided tests.

We used the SAS statistical package (version 6.12), to correlate odds ratios of experimental versus reference treatment with corresponding blood pressure differences. For these calculations, odds ratios were logarithmically transformed. The regression lines were weighted by the inverse of the variance of individual odds ratios. Net treatment effects on blood pressure were calculated by subtraction of the mean change in the experimental group (follow-up minus baseline) from the corresponding mean change in the reference group. If blood pressure at entry differed between groups in the same study, the average pressure was taken as baseline. ${ }^{4}$
Number of events old/new

\section{Results}

Heterogeneity

We assessed heterogeneity in results of trials comparing old with new antihypertensive drugs (table 1). The trials included 33325 patients randomly assigned old drugs and 29280 assigned initial antihypertensive treatment with new drugs.

Because the ALLHAT report ${ }^{10}$ did not include separate information on cardiovascular mortality, this trial could not be included in the review of fatal endpoints (figure 1 and table 2). Cause-specific cardiovascular mortality was not reported for MIDAS, ${ }^{3} \mathrm{NICS},{ }^{5}$ or VHAS. ${ }^{63}$ In trials with information on one or more of the fatal outcomes, ${ }^{3-6,8,9,16,63}$ such outcomes did not differ between new and old drugs apart from a $3 \cdot 22(95 \%$ CI $1 \cdot 12-11 \cdot 2$,

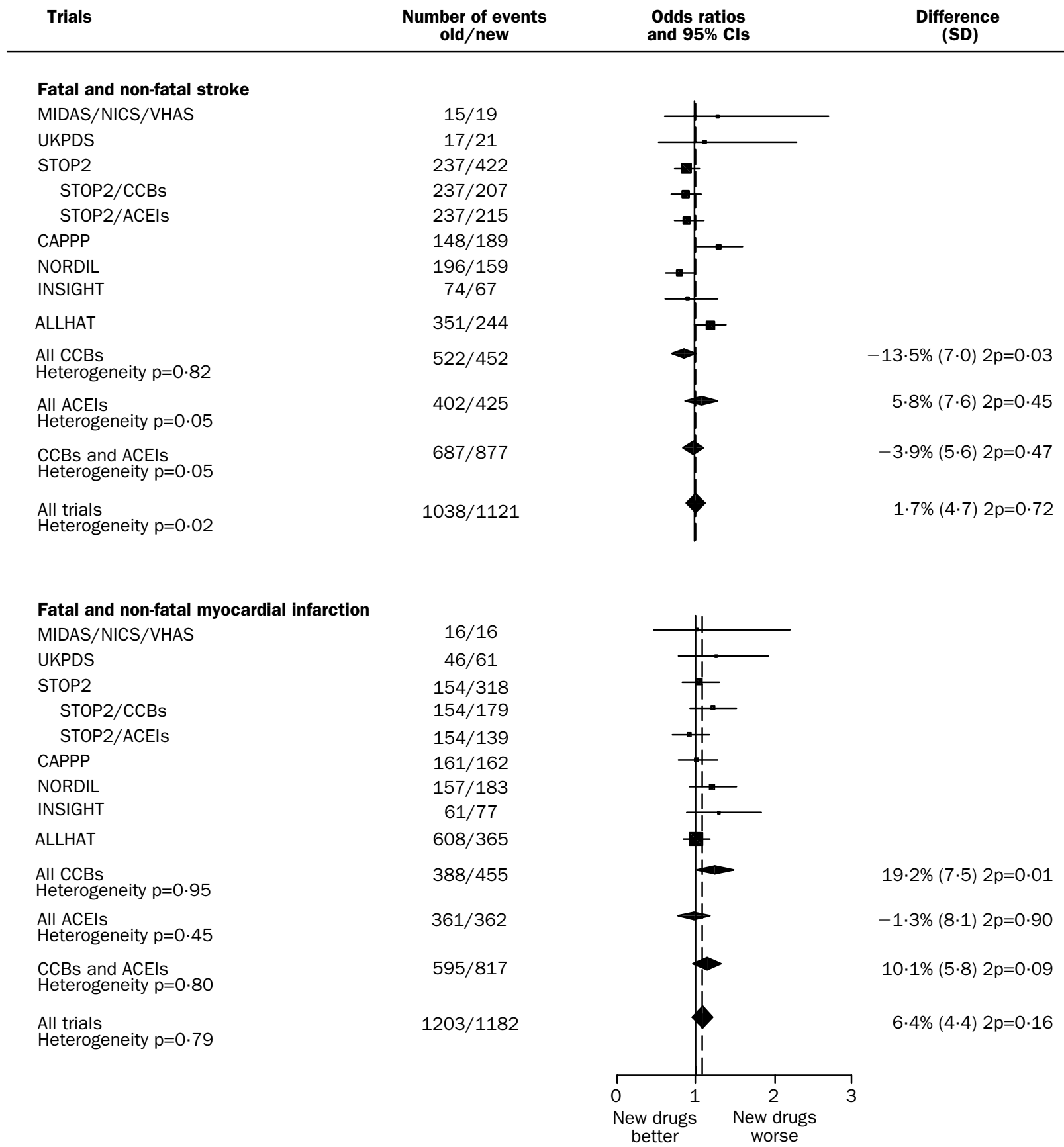

Figure 2: Effects of antihypertensive treatment on fatal and non-fatal stroke and myocardial infarction in trials comparing old with new drugs

Fatal and non-fatal myocardial infarction includes sudden death. Acronyms and references of trials are in the appendix. 


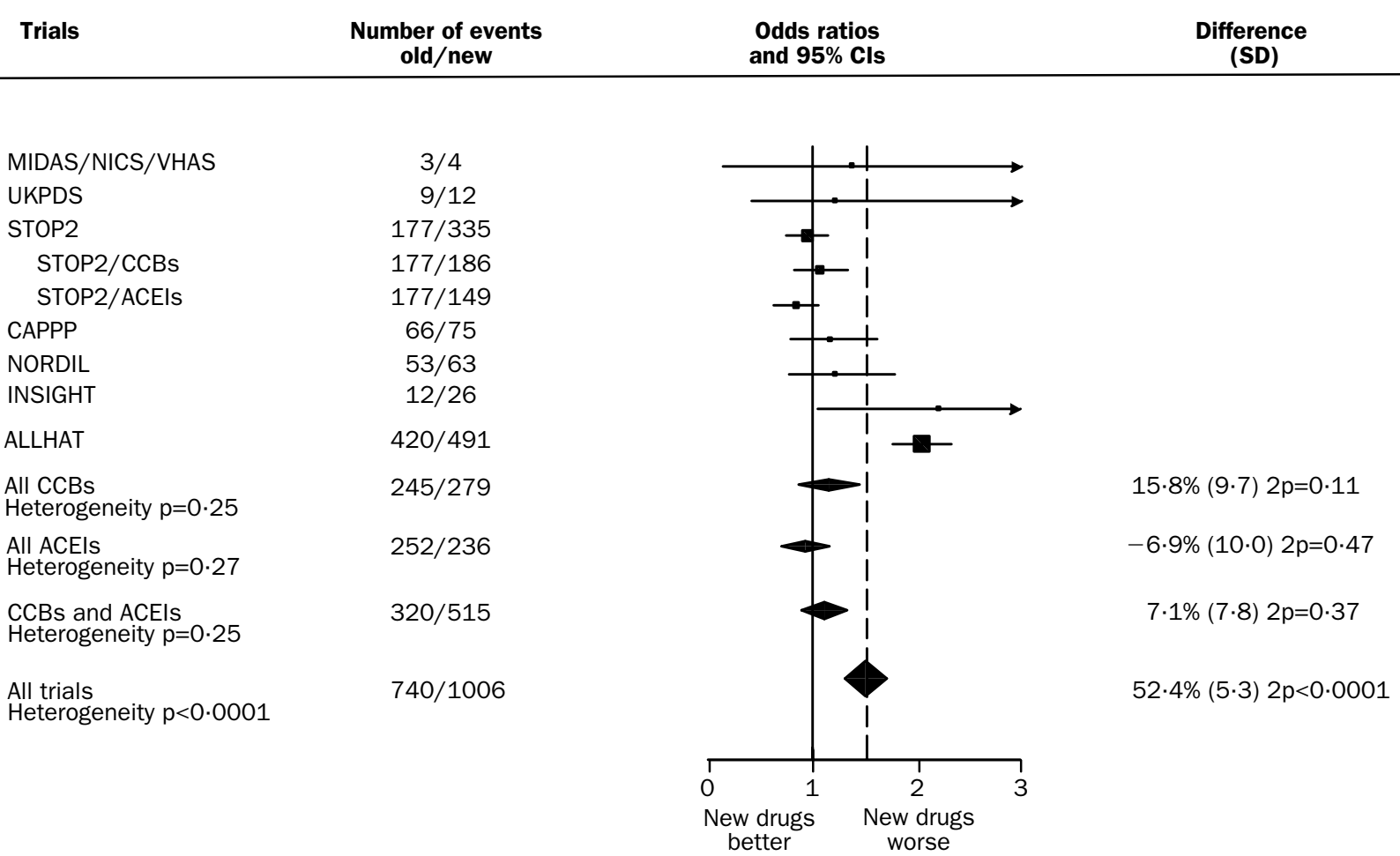

Figure 3: Effects of antihypertensive treatment on fatal and non-fatal congestive heart failure in trials comparing old with new drugs Acronyms and references of trials are in the appendix.
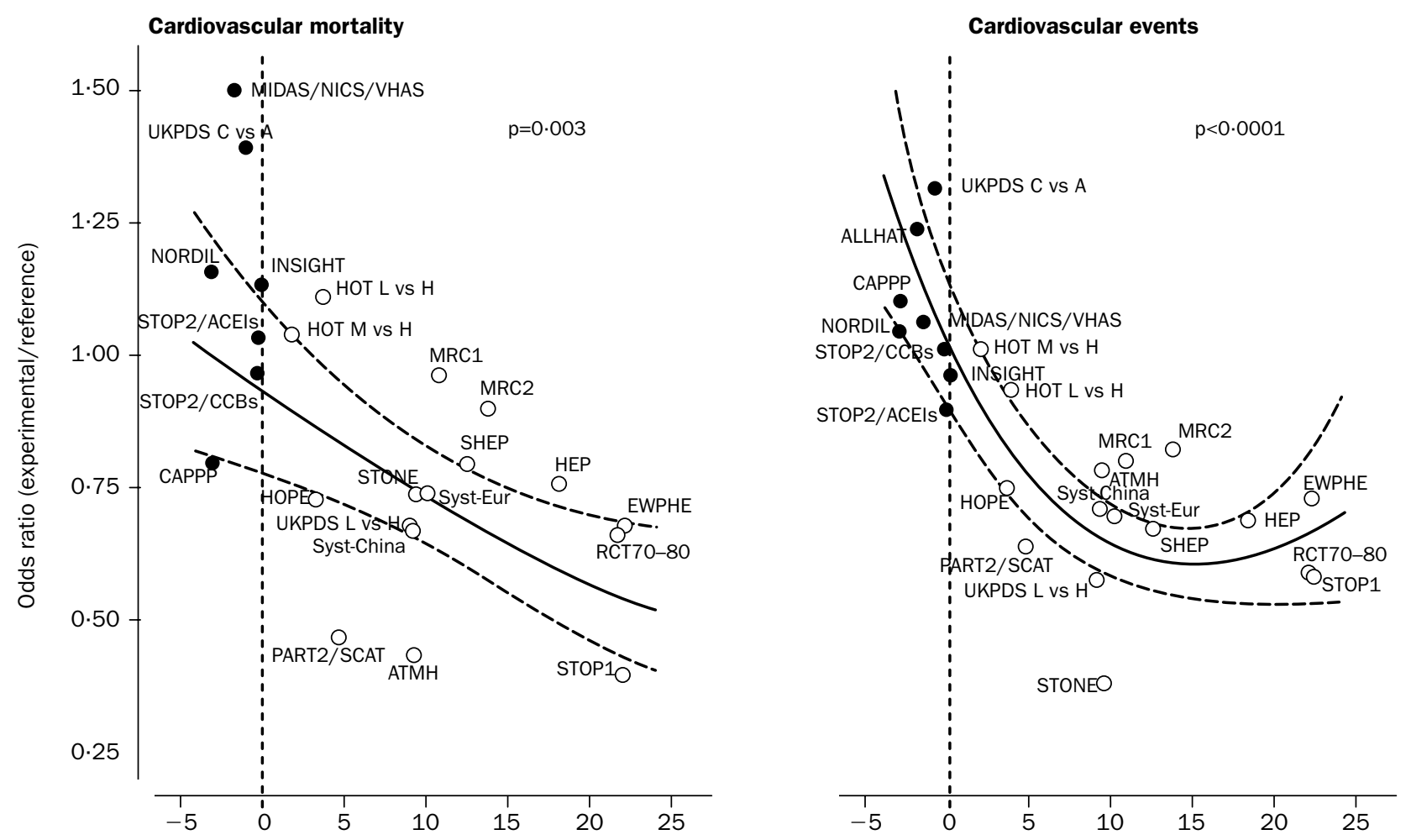

Difference (reference minus experimental) in systolic pressure $(\mathrm{mm} \mathrm{Hg})$

Figure 4: Relation between odds ratios for cardiovascular mortality and all cardiovascular events, and corresponding differences in systolic blood pressure

Odds ratios were calculated for experimental versus reference treatment. Blood pressure differences were calculated by subtracting achieved levels in experimental groups from those in reference groups. Negative differences indicate tighter blood pressure control on reference treatment. Regression lines were plotted with $95 \% \mathrm{Cl}$ and were weighted for the inverse of the variance of individual odds ratios. Closed symbols denote trials that compared new with old drugs. Acronyms and references of trials are in the appendix. 

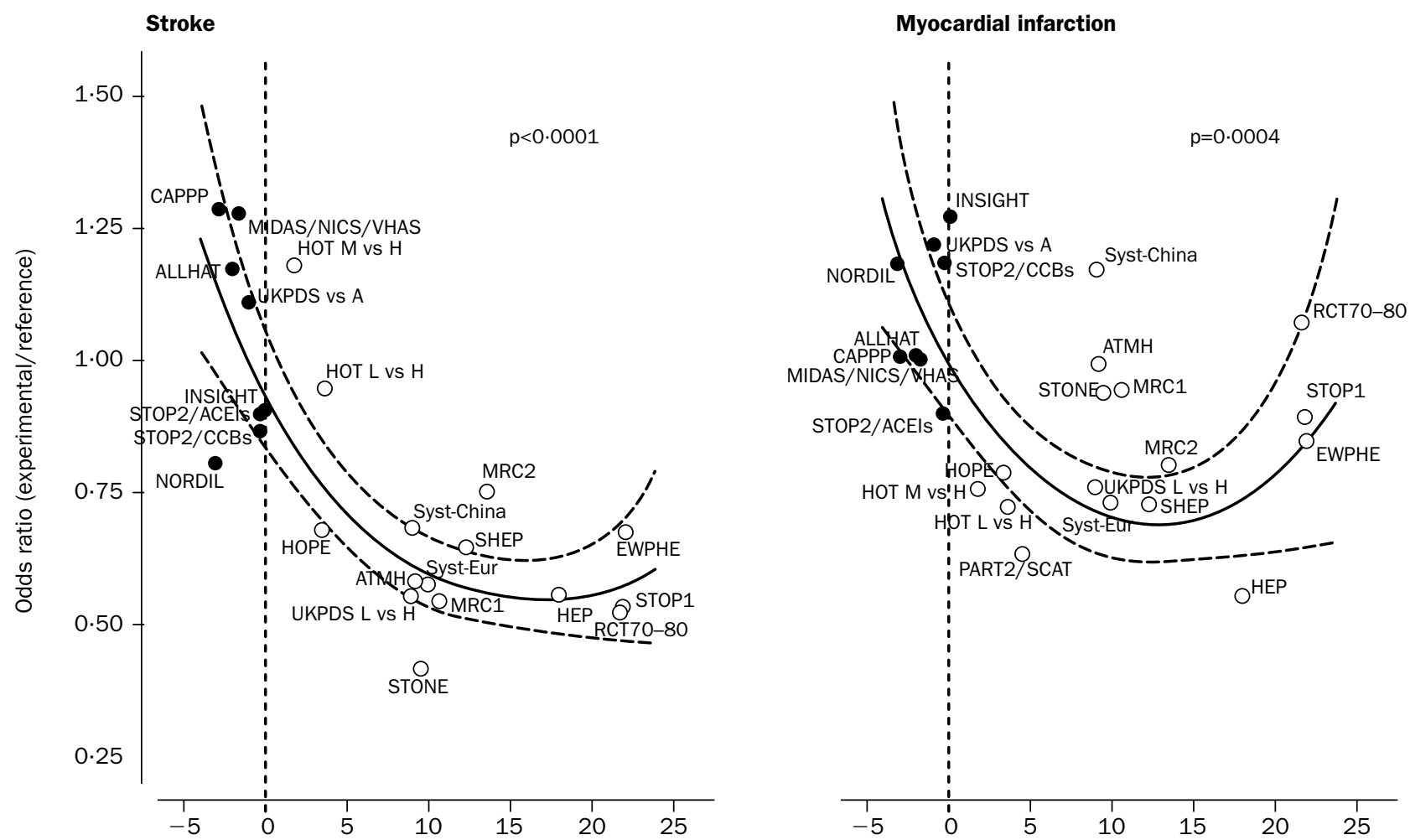

Difference (reference minus experimental) in systolic pressure ( $\mathrm{mm} \mathrm{Hg}$ )

Figure 5: Relation between odds ratios for fatal and non-fatal stroke and fatal and non-fatal myocardial infarction, and corresponding differences in systolic blood pressure

Fatal and non-fatal myocardial infarction includes sudden death. Odds ratios were calculated for experimental versus reference treatment. Blood pressure differences were calculated by subtracting achieved levels in experimental groups from those in reference groups. Negative differences indicate tighter blood pressure control on reference treatment. Regression lines were plotted with $95 \% \mathrm{Cl}$ and were weighted for the inverse of the variance of individual odds ratios. Closed symbols denote trials that compared new with old drugs. Acronyms and references of trials are in the appendix.

$\mathrm{p}=0.03)$ increase in fatal myocardial infarction on treatment with nifedipine GITS (gastrointestinal transfer system) ${ }^{8}$ Heterogeneity was not significant by Zelen's test in any of the pooled mortality results (table 2). The new drugs were as effective as the old ones in prevention of cardiovascular mortality or deaths from stroke and myocardial infarction with or without sudden death.

With respect to fatal combined with non-fatal outcomes, trials had significant heterogeneity, which was largely attributable to higher risk of cardiovascular complications (figure 1), stroke (figure 2), and congestive heart failure (figure 3) with doxazosin than with chlorthalidone in ALLHAT. ${ }^{10}$ For these events, odds ratios were $1 \cdot 25(1 \cdot 17-1 \cdot 33, \mathrm{p}<0 \cdot 0001), 1 \cdot 19(1 \cdot 01-1 \cdot 40$, $\mathrm{p}=0.04)$, and $2.04(1 \cdot 79-2 \cdot 32, \mathrm{p}<0 \cdot 0001)$, respectively ${ }^{10}$ After exclusion of ALLHAT, slight heterogeneity persisted in overall risk of cardiovascular complications with ACE inhibitors compared with old drugs (figure 1, $p=0.03$ ). This result was attributable to higher risk of stroke $^{4}$ in patients randomly assigned captopril (figure 2): odds ratio $1 \cdot 25(1 \cdot 01-1 \cdot 55, \mathrm{p}=0 \cdot 04)$. In individual trials, patients allocated diltiazem ${ }^{9}$ had a lower risk of stroke

\begin{tabular}{|c|c|c|c|c|c|c|}
\hline & \multicolumn{6}{|c|}{ Variance explained and corresponding probability } \\
\hline & \multirow{2}{*}{$\frac{\text { Overall model }}{\mathrm{R}^{2}}$} & \multirow[b]{2}{*}{$\mathrm{p}$} & \multicolumn{2}{|c|}{ Initial blood pressure } & \multicolumn{2}{|c|}{ Blood pressure difference } \\
\hline & & & $\mathrm{R}^{2}$ & $\mathrm{p}$ & $\mathrm{R}^{2}$ & $\mathrm{p}$ \\
\hline \multicolumn{7}{|c|}{$\begin{array}{l}\text { Outcome } \\
\text { Cardiovascular mortality }\end{array}$} \\
\hline Systolic & 0.47 & 0.002 & $0 \cdot 11$ & 0.05 & 0.36 & 0.0004 \\
\hline Diastolic & 0.42 & 0.005 & $0 \cdot 10$ & 0.08 & 0.32 & 0.001 \\
\hline \multicolumn{7}{|c|}{ Cardiovascular events } \\
\hline Systolic & 0.66 & $<0.0001$ & 0.006 & 0.56 & 0.65 & $<0.0001$ \\
\hline Diastolic & 0.51 & 0.002 & $\sim 0$ & 0.99 & 0.51 & 0.001 \\
\hline \multicolumn{7}{|l|}{ Stroke } \\
\hline Systolic & $0 \cdot 71$ & $<0 \cdot 0001$ & 0.004 & 0.48 & $0 \cdot 71$ & $<0.0001$ \\
\hline Diastolic & 0.66 & 0.0001 & 0.007 & 0.55 & 0.65 & $<0.0001$ \\
\hline \multicolumn{7}{|c|}{ Myocardial infarction } \\
\hline Systolic & 0.55 & 0.001 & 0.02 & 0.37 & 0.53 & 0.0005 \\
\hline Diastolic & 0.54 & 0.001 & 0.09 & 0.06 & 0.45 & 0.002 \\
\hline
\end{tabular}

Every metaregression model included blood pressure at entry and blood pressure difference between study groups as independent variables and was weighted by the inverse of the variance of individual odds ratios.

Table 3: Variance explained by initial blood pressure and blood pressure difference 


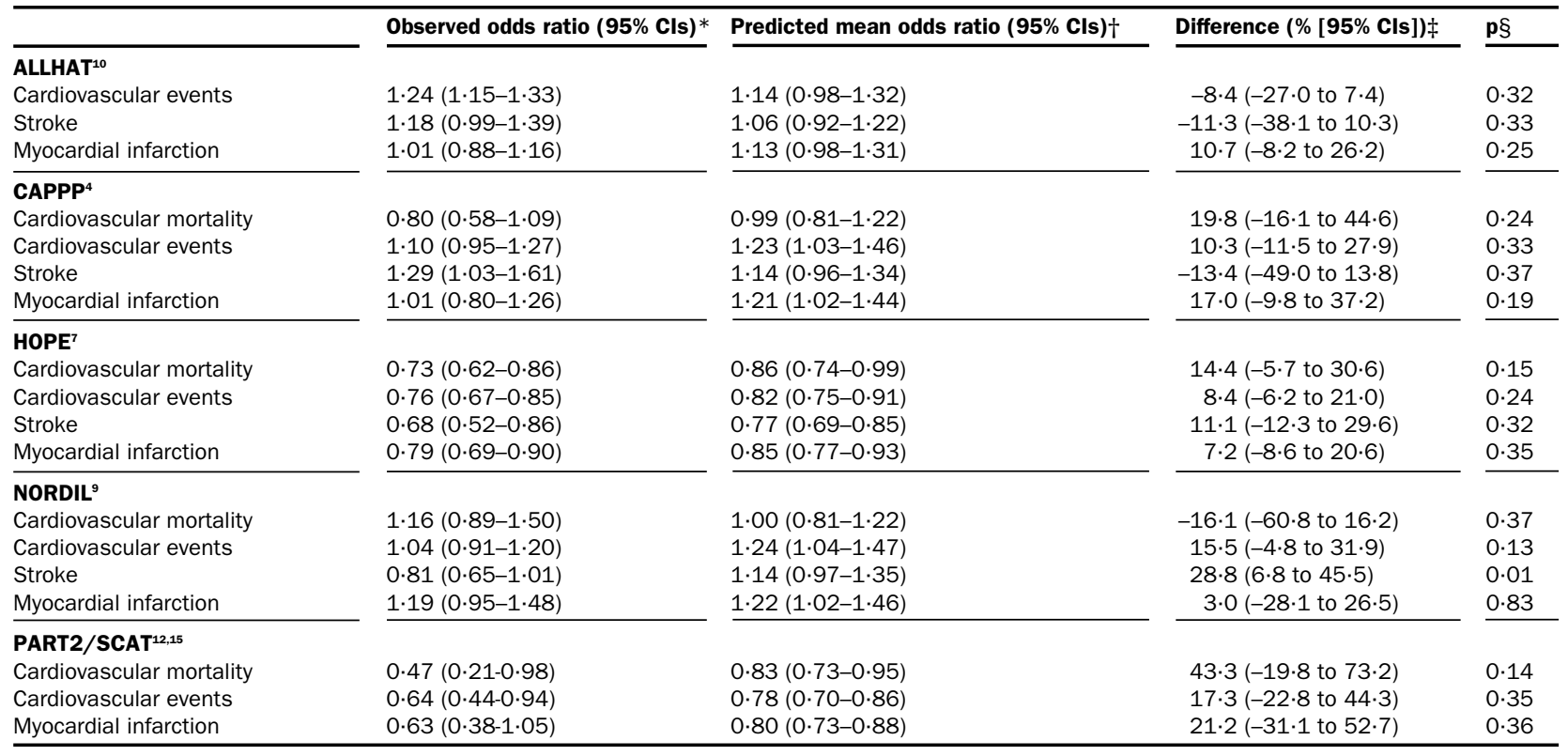

*Odds ratio reported in the published articles. †Mean odds ratio $(95 \% \mathrm{Cl}$ ) predicted by metaregression lines (figures 4 and 5 ). $\ddagger$ Difference between predicted minus observed odds ratio $(95 \% \mathrm{Cl})$ expressed in percent of predicted odds ratio. §Significance of difference between observed and predicted odds ratios.

Table 4: Observed odds ratios and odds ratios predicted by differences in systolic blood pressure in metaregression

than their counterparts given old classes of drugs (figure $2)$ : odds ratio $0 \cdot 80(0 \cdot 65-0 \cdot 99, \mathrm{p}=0 \cdot 04)$, but this result did not lead to significant heterogeneity among studies including calcium-channel blockers.

After exclusion of ALLHAT, ${ }^{10}$ overall cardiovascular risk did not differ between patients randomised to diuretics or $\beta$-blockers compared with those allocated initial treatment with calcium-channel blockers or ACE inhibitors (figure 1). However, in patients randomised to calcium-channel blockers, reduction in risk of stroke was greater (difference $13.5 \%, 1 \cdot 3-24 \cdot 2, \mathrm{p}=0.03$, figure 2 ), but reduction in risk of myocardial infarction was less $(19 \cdot 2 \%, 3 \cdot 5-37 \cdot 3 \%, \mathrm{p}=0.01$, figure 2) than in those in whom treatment was started with old drugs. In patients given ACE inhibitors, risk reductions were similar for stroke and for myocardial infarction (figure 2).

In trials leading to significant heterogeneity, ${ }^{4,10}$ or with significant differences in overall risk of cardiovascular events ${ }^{10}$ or cause-specific cardiovascular complications, $, 4,9,10$ there were differences in achieved systolic pressure between groups of $2 \mathrm{~mm} \mathrm{Hg}$ or more (table 1). Therefore, we decided to investigate further the relation between odds ratios expressing benefit and achieved blood pressure differences by use of most of the published evidence.

\section{Blood pressure reduction}

The 27 studies in our metaregression included 136124 patients. These studies consisted of nine actively controlled trials (table 1 ) $;^{3-6,8-10,14,16}$ HOT, ${ }^{26}$ in which different levels of blood pressure control were investigated; three placebo-controlled trials in isolated systolic hypertension; $;^{39-41}$ three placebo-controlled trials in normotensive or hypertensive patients at high cardiovascular risk; ${ }^{7,12,15}$ and 11 older trials testing efficacy of antihypertensive drugs against no treatment. The characteristics of these 11 trials have been reviewed. ${ }^{17,18,20,21,24,25}$

The metaregression line between odds of an event and differences in systolic pressure between study groups was linear for cardiovascular mortality (figure 4) and curvilinear for all cardiovascular events (figure
4), stroke (figure 5), and myocardial infarction including sudden death (figure 5). Blood pressure at baseline contributed less to explained variance than blood pressure differences during follow-up (table 3). Consequently, adjustment of metaregression lines for baseline systolic pressure did not substantially alter their position.

Systolic pressure differences seen in individual studies are shown in table 1 and figures 4 and 5 . Blood pressure after enrolment was reported at near mean $^{5,10,12,30-33,49}$ or median ${ }^{40,41}$ follow-up in ten trials, at end of follow-up in four, ${ }^{6,7,36,63}$ and as average of whole follow-up in $13.3,8,9,15,16,26,28,29,34,35,37-39$ In addition to ALLHAT ${ }^{10}$ CAPPP ${ }^{4}$ and NORDIL $^{9}$ (table 1), differences in achieved systolic pressure, diastolic pressure, or both between study groups (reference minus experimental drug) were significant in hypertension trials that included less treated ${ }^{26,27}$ or untreated $^{28-41}$ controls, and in MIDAS (difference -3.5 [systolic]/about 0 [diastolic] $\mathrm{mm} \mathrm{Hg}){ }^{3} \mathrm{HOPE}$ $(-3 \cdot 3 /-1 \cdot 0 \mathrm{~mm} \mathrm{Hg}),{ }^{7}$ PART2 $(-5 /-4 \mathrm{~mm} \mathrm{Hg}),{ }^{12}$ and SCAT $(-4 /-2 \mathrm{~mm} \mathrm{Hg}) .{ }^{15}$ For MIDAS $^{3}$ combined with $\mathrm{NICS}^{5}$ and VHAS, ${ }^{63}$ systolic/diastolic differences were $-1 \cdot 8$ /about $0 \mathrm{~mm} \mathrm{Hg}$. For PART2 ${ }^{12}$ combined with SCAT, ${ }^{15}$ these differences were $-4 \cdot 6 /-3 \cdot 1 \mathrm{~mm} \mathrm{Hg}$. Differences between observed odds ratios and those predicted by metaregression lines (table 4) were not significant apart from in NORDIL, ${ }^{9}$ in which risk of stroke was lower in patients on diltiazem than on old drugs despite systolic pressure that was $3 \cdot 1 \mathrm{~mm} \mathrm{Hg}$ higher on diltiazem (figure 5 and table 4). ALLHAT ${ }^{10}$ and $\mathrm{HOPE}^{7}$ were large trials (table 1) with significant differences in on-treatment systolic pressure between randomised groups. STONE ${ }^{34}$ and Syst-China ${ }^{41}$ used alternate non-randomised allocation of consecutive patients to placebo on active treatment. Sensitivity analyses in which ALLHAT $^{10}$ and HOPE, ${ }^{7}$ or STONE $^{34}$ and Syst-China ${ }^{41}$ were excluded only slightly changed the position of the regression lines and their $95 \%$ CIs, and therefore did not alter the results shown in table 4 . 


\section{Discussion}

Our main finding was that results of outcome trials for antihypertensive drugs can be explained by blood pressure differences between randomised groups. All antihypertensive drugs had similar long-term efficacy and safety. Our results show the desirability of lowering blood pressure as much as possible to achieve the greatest reduction in cardiovascular complications. These findings are in accord with, and add to, earlier reports. ${ }^{17,18}$ Indeed, in older patients with isolated systolic hypertension, ${ }^{17}$ lowering systolic blood pressure by $10 \mathrm{~mm} \mathrm{Hg}$ and diastolic pressure by $4 \mathrm{~mm} \mathrm{Hg}$ reduced risk of stroke and myocardial infarction by $30 \%$ and $23 \%$, respectively. In patients with predominantly diastolic hypertension, ${ }^{18}$ corresponding benefits produced by a 5-6 $\mathrm{mm} \mathrm{Hg}$ decline in diastolic pressure were $38 \%$ and $16 \%$, respectively.

Because in most trials study groups were similar at entry, we did not need to adjust for characteristics of patients in our metaregression. Furthermore, blood pressure at entry explained little additional variance. After adjustment for baseline blood pressure, our conclusions remained unaltered. The stage of follow-up at which we assessed blood pressure differences depended on what was reported in the studies. However, our inclusion criteria specified a minimum follow-up of 2 years. In most trials, blood pressure differences between study groups were already at their greatest at 6 months of follow-up. Moreover, our metaregression results suggested that for fatal and non-fatal outcomes combined, a substantial part of drug benefit was already achieved by modest $5 \mathrm{~mm} \mathrm{Hg}$ differences in systolic pressure. Almost all possible benefit of antihypertensive treatment was seen at systolic pressure gradients of about $15 \mathrm{~mm} \mathrm{Hg}$. However, these results should be interpreted cautiously. Indeed, these differences in systolic pressure do not represent absolute declines in blood pressure, because they were expressed relative to blood pressure changes in controls. Furthermore, the 5357 patients randomised in trials in which systolic difference exceeded $15 \mathrm{~mm} \mathrm{Hg}$ represented only $3.9 \%$ of patients included in our metaregression analysis. We also did not define a priori the hypothesis of a curvilinear relation between odds ratios and achieved differences in systolic pressure.

In $\mathrm{HOPE}^{7,62}$ around $90 \%$ of patients had previous cardiovascular complications. Treatment with ramipril reduced cardiovascular mortality and incidence of stroke, myocardial infarction, and congestive heart failure. ${ }^{7}$ Systolic pressure differed by $3.3 \mathrm{~mm} \mathrm{Hg}$ between ramipril and placebo groups. ${ }^{7}$ Endothelial actions of ramipril $^{62}$ have been suggested as stabilisers of atherosclerotic plaques in the large arteries. $^{64}$ ACE inhibitors have proven benefit in patients with heart failure ${ }^{65}$ or dysfunction of the left ventricle. ${ }^{66}$ However, our results suggest that in fact blood pressure could have accounted for most-if not all-benefits seen in HOPE patients allocated ramipril. Furthermore, results of two further placebocontrolled trials of ACE inhibition in high-risk patients $^{12,15}$ also did not significantly deviate from benefits predicted by differences in systolic pressure between randomised groups.

Two large Scandinavian trials ${ }^{4,6}$ also did not produce any evidence that ACE inhibitors would provide better cardiovascular protection than diuretics, $\beta$-blockers, or both. By contrast, risk of stroke was $18 \%$ higher in patients randomised to initial treatment with captopril than in those given old drugs. ${ }^{4}$ Interpretation of these results is difficult, because at randomisation blood pressure was already $2 \cdot 2 / 1.7 \mathrm{~mm} \mathrm{Hg}$ higher in patients in the captopril group ${ }^{4,57}$ and the blood pressure gradient was maintained during follow-up. After extrapolation of results from the Framingham Heart Study and the second National Health and Nutrition Examination Survey, ${ }^{19}$ researchers speculated that a $2 \mathrm{~mm} \mathrm{Hg}$ difference in blood pressure could account for a $15 \%$ difference in stroke risk, but they could not exclude the possibility that old drugs were more effective in prevention of stroke. ${ }^{4}$ Our results suggest that less blood pressure control on captopril could explain the higher risk of stroke. ${ }^{4}$

Patients randomly assigned doxazosin had higher rates of stroke and congestive heart failure than those on chlorthalidone. ${ }^{10}$ The investigators suggested that participants' blood pressure differences were sufficient to explain the higher incidence of stroke on doxazosin, but that these differences could account for only a $10-20 \%$ increase in occurrence of heart failure-not a doubling of the rate..$^{10}$ Our metaregression analysis results showed that the blood pressure gradient was indeed sufficient to explain the higher risk of stroke on doxazosin. Furthermore, before randomisation, $90 \%$ of the patients were on antihypertensive drugs, presumably diuretics in many instances. Thus, ALLHAT not only tested doxazosin versus chlorthalidone, but also tested stopping versus continuing a diuretic in a group of hypertensive patients, of whom a considerable proportion must have been at high risk of heart failure. These factors probably explain why Kaplan-Meier curves for heart failure started to diverge immediately after randomisation. ${ }^{10}$ The most important point, however, is that doxazosin achieved similar results to chlorthalidone for the primary outcome, which was coronary heart disease, despite poorer blood pressure control on doxazosin. ${ }^{10}$

The results of our quantitative overview of actively controlled trials in hypertension showed that calcium-channel blockers and ACE inhibitors reduced fatal and non-fatal outcomes as effectively as diuretics or $\beta$-blockers. Compared with older drug classes, calcium-channel blockers and ACE inhibitors gave the same overall protection against cardiovascular complications, but calcium-channel blockers provided more reduction in risk of stroke and less reduction in risk of myocardial infarction. With metaregression, we showed that diltiazem compared with diuretics, $\beta$-blockers, or both, decreased risk of stroke despite higher systolic pressure. Furthermore, stroke results were not heterogeneous between NORDIL $^{9}$ and other actively controlled studies with calcium-channel blockers. ${ }^{3,5,6,8,863}$ Nevertheless, these cause-specific results must be interpreted with caution because confidence intervals were wide, and because results might be attributable not only to the drugs under study, but also to characteristics of patients. ${ }^{67}$ Selective recruitment of middle-aged patients with type 2 diabetes, ${ }^{53}$ older high-risk hypertensive patients, ${ }^{8}$ and elderly patients with isolated systolic hypertension ${ }^{39,40,56,59}$ probably explains why rates of myocardial infarction varied from $6 \cdot 3^{8}$ to $32 \cdot 2^{56}$ cases per 1000 patient-years, 
and why results for prevention of myocardial infarction were contradictory.

Our overview should be interpreted within the context of its limitations. As in all meta-analyses that start from published summary statistics, we achieved less standardisation than is attainable in quantitative overviews based on individual patients' data. Thus, not only participants' characteristics, but also the definition and validation of endpoints in individual trials might have affected our estimates of risk in treated and untreated patients. Masked validation in open trials ${ }^{4,6,9,16,26,28,49}$ does not remove the possibility that previous knowledge of treatment allocation resulted in selective over-reporting or underreporting of events. Furthermore, we chose not to combine weaker coronary endpoints such as angina pectoris with myocardial infarction, sudden death, or both. Conversely, to allow interpretation of ALLHAT results $^{10}$ against the background of all available evidence, we included heart failure in all cardiovascular events, which can also be looked upon as a weaker clinical endpoint. Finally, our analysis does not indicate to what extent blood pressure should be lowered. This issue remains unsettled because the studies that we analysed did not account for systolic pressure or pulse pressure, ${ }^{26,49}$ or had blood pressure targets that were too high. ${ }^{27}$ Additionally, individual tailoring of antihypertensive drugs compared with fixed selection, titration, and combination of treatments was not investigated in any trial.

In conclusion, in trials in hypertension and highrisk patients, blood pressure gradients largely accounted for most differences in outcome. These findings emphasise the desirability of blood pressure control. On average, all antihypertensive drugs have similar long-term efficacy and safety. Compared with diuretics and $\beta$-blockers, calcium-channel blockers might protect more against stroke than myocardial infarction, resulting in an overall cardiovascular benefit similar to that of old classes of antihypertensive drugs. The hypothesis that in the reviewed studies ACE inhibitors might affect outcome beyond their blood-pressure-lowering effects remains unproved. On the contrary, in the PROGRESS trial, $^{68}$ monotherapy with perindopril lowered systolic pressure by $5 \mathrm{~mm} \mathrm{Hg}$ more than placebo, but unexpectedly ${ }^{69}$ did not reduce the risk of cardiovascular events or stroke recurrence.

\section{Contributors}

Jan Staessen and Ji-Guang Wang extracted data and wrote the manuscript. Ji-Guang Wang did statistical calculations with the help of Lutgarde Thijs and Jan Staessen. All authors reviewed the manuscript and approved the final version.

\section{Acknowledgments}

Ji-Guang Wang was supported by the bilateral scientific and technical collaboration between the People's Republic of China and Flanders (contract number BIL98/15). We thank E Den Hond. W H Birkenhäger (Erasmus University, Rotterdam, the Netherlands) provided helpful comments.

\section{References}

1 Casiglia E, Spolaore P, Mazza A, et al. Effect of 2 different therapeutic approaches on total and cardiovascular mortality in a Cardiovascular Study in the Elderly. Fpn Heart f7 1994; 35: $589-600$

2 Neaton JD, Grimm JRH, Prineas RJ, et al. Treatment of mild hypertension study: final results. $7 A M A$ 1993; 270: 713-24.
3 Borhani NO, Mercuri M, Borhani PA, et al. Final outcome results of the multicenter isradipine diuretic atherosclerosis study (MIDAS). A randomized controlled trial. $7 A M A$ 1996; 276: 785-91.

4 Hansson L, Lindholm LH, Niskanen L, et al. Effect of angiotensin-converting-enzyme inhibition compared with conventional therapy on cardiovascular morbidity and mortality in hypertension: the Captopril Prevention Project (CAPPP) randomised trial. Lancet 1999; 353: 611-16.

5 National Intervention Cooperative Study in Elderly Hypertensives Study Group. Randomized double-blind comparison of a calcium antagonist and a diuretic in elderly hypertensives. Hypertension 1999; 34: 1129-33.

6 Hansson L, Lindholm LH, Ekbom T, et al. Randomised trial of old and new antihypertensive drugs in elderly patients: cardiovascular mortality and morbidity in the Swedish Trial in Old Patients with Hypertension-2 study. Lancet 1999; 354: 1751-56.

7 The Heart Outcomes Prevention Evaluation Study Investigators. Effects of an angiotensin-converting-enzyme inhibitor, ramipril, on cardiovascular events in high-risk patients. $N$ Engl f Med 2000; 342: $145-53$.

8 Brown MJ, Palmer CR, Castaigne A, et al. Morbidity and mortality in patients randomised to double-blind treatment with long-acting calcium-channel blocker or diuretic in the International Nifedipine GITS Study: Intervention as a Goal in Hypertensive Treatment (INSIGHT). Lancet 2000; 356: 366-72.

9 Hansson L, Hedner T, Lund-Johansen P, et al. Randomised trial of effects of calcium antagonists compared with diuretics and $\beta$-blockers on cardiovascular morbidity and mortality in hypertension: the Nordic Diltiazem (NORDIL) study. Lancet 2000; 356: 359-65.

10 The ALLHAT Officers and Coordinators for the ALLHAT Collaborative Research Group. Major cardiovascular events in hypertensive patients randomized to doxazosin vs chlorthalidone. The Antihypertensive and Lipid-Lowering Treatment to Prevent Heart Attack Trial (ALLHAT). FAMA 2000; 283: 1967-75.

11 Cashin-Hemphill L, Holmvang G, Chan RC, et al. Angiotensinconverting enzyme inhibition as anti-atherosclerotic therapy: no answer yet. Am f Cardiol 1999; 83: 43-47.

12 MacMahon S, Sharpe N, Gamble G, et al. Randomized, placebo-controlled trial of the angiotensinconverting enzyme inhibitor, ramipril, in patients with coronary or other occlusive arterial disease. $f$ Am Coll Cardiol 2000; 36: 438-43.

13 Pitt B, Byington RP, Furberg CD, et al. Effect of amlodipine on the progression of atherosclerosis and the occurrence of clinical events. Circulation 2000; 102: 1503-10.

14 Zanchetti A, Agabiti Rosei E, Dal Palù C, et al. The Verapamil in Hypertension and Atherosclerosis Study (VHAS): results of long-term randomized treatment with either verapamil or chlorthalidone on carotid intima-media thickness. 7 Hypertens 1998; 16: 1667-76

15 Teo KK, Burton JR, Buller CE, et al. Long-term effects of cholesterol lowering and angiotensin-converting enzyme inhibition on coronary atherosclerosis. The Simvastatin/Enalapril Coronary Atherosclerosis Trial (SCAT). Circulation 2000; 102: 1748-54.

16 UK Prospective Diabetes Study Group. Efficacy of atenolol and captopril in reducing risk of macrovascular and microvascular complications in type 2 diabetes: UKPDS 39. BMF 2000; 317: 713-20.

17 Staessen JA, Gasowski J, Wang JG, et al. Risks of untreated and treated isolated systolic hypertension in the elderly: meta-analysis of outcome trials. Lancet 2000; 355: 865-72.

18 Collins R, MacMahon S. Blood pressure, antihypertensive drug treatment and the risks of stroke and of coronary heart disease. Br Med Bull 1994; 50: 272-98.

19 Cook NR, Cohen J, Hekbert PR, Hennekens CH. Implications of small reductions in diastolic pressure for primary prevention. Arch Intern Med 1995; 155: 701-06.

20 Blood Pressure Lowering Treatment Trialists' Collaboration. Effects of ACE inhibitors, calcium antagonists, and other bloodpressure-lowering drugs: results of prospectively designed overviews of randomised trials. Lancet 2000; 355: 1955-64.

21 Pahor M, Psaty BM, Alderman MH, et al. Health outcomes associated with calcium antagonists compared with other first-line antihypertensive therapies: a meta-analaysis of randomised controlled trials. Lancet 2000; 356: 1949-54. 
22 Staessen J, Amery A, Fagard R. Editorial review. Isolated systolic hypertension in the elderly. F Hypertens 1990; 8: 393-405

23 Swales JD. Systolic versus diastolic pressure: paradigm shift or cycle? f Hum Hypertens 2000; 14: 477-79.

24 Thijs L, Fagard R, Lijnen P, Staessen J, Van Hoof R, Amery A. Why is antihypertensive drug therapy needed in elderly patients with systolodiastolic hypertension? F Hypertens 1994; 12 (suppl 6): S25-S34.

25 Staessen JA, Wang JG. Characteristics of published, ongoing, and planned outcome trials in hypertension. In: Oparil S, Weber MA, eds. Hypertension: a companion to Brenner and Rector's The Kidney. Philadelphia: W B Saunders Co, 1999: 341-59.

26 Hansson L, Zanchetti A, Carruthers SG, et al. Effects of intensive blood-pressure lowering and low-dose aspirin in patients with hypertension: principal results of the Hypertension Optimal Treatment (HOT) randomised trial. Lancet 1998; 351: 1755-62.

27 UK Prospective Diabetes Study Group. Tight blood pressure control and risk of macrovascular and microvascular complications in type 2 diabetes: UKPDS 38. BMF 1998; 317: 703-13.

28 Coope J, Warrender TS. Randomised trial of treatment of hypertension in elderly patients in primary care. $B M 7$ 1986; 293: 1145-51.

29 Helgeland A. Treatment of mild hypertension: a five year controlled drug trial. Am f Med 1980; 69: 725-32.

30 Amery A, Birkenhäger W, Brixko P, et al. Mortality and morbidity results from the European Working Party on High Blood Pressure in the Elderly trial. Lancet 1985; 1: 1349-54.

31 Dahlöf B, Lindholm LH, Hansson L, Scherstén B, Ekbom T, Wester PO. Morbidity and mortality in the Swedish Trial in Old Patients with Hypertension (STOP-Hypertension). Lancet 1991; 338: $1281-85$.

32 MRC Working Party. Medical Research Council trial of treatment of hypertension in older adults: principal results. BMF 1992; 304: 405-12.

33 Medical Research Council Working Party. MRC trial of treatment of mild hypertension: principal results. BMF 1985; 291: 97-104.

34 Gong L, Zhang W, Zhu Y, et al. Shanghai trial of nifedipine in the elderly (STONE). $f$ Hypertens 1996; 14: 1237-45.

35 Management Committee. The Australian therapeutic trial in mild hypertension. Lancet 1980; 1: 1261-67.

36 Hypertension-Stroke Cooperative Study Group. Effect of antihypertensive treatment on stroke recurrence. $\mathcal{F A M A ~ 1 9 7 4 ; ~}$ 229: 409-18.

37 US Public Health Service Hospitals Cooperative Study Group (McFate Smith WM). Treatment of mild hypertension: results of a ten-year intervention trial. Circ Res 1977; 40 (suppl 1): 98-105.

38 Veterans Administration Cooperative Study Group on Antihypertensive Agents. Effect of treatment on morbidity in hypertension: results in patients with diastolic blood pressure averaging 115-129 mm Hg. FAMA 1967; 202: 116-22.

39 SHEP Cooperative Research Group. Prevention of stroke by antihypertensive drug treatment in older persons with isolated systolic hypertension. Final results of the Systolic Hypertension in the Elderly Program (SHEP). $F A M A$ 1991; 265: 3255-64.

40 Staessen JA, Fagard R, Thijs L, et al. Randomised double-blind comparison of placebo and active treatment for older patients with isolated systolic hypertension. Lancet 1997; 350: 757-64.

41 Liu L, Wang JG, Gong L, Liu G, Staessen JA, for the Systolic Hypertension in China (Syst-China) Collaborative Group. Comparison of active treatment and placebo for older patients with isolated systolic hypertension. F Hypertens 1998; 16: 1823-29.

42 Sprackling ME, Mitchell JRA, Short AH, Watt G. Blood pressure reduction in the elderly: a randomised controlled trial of methyldopa. BMF 1981; 283: 1151-53.

43 Veterans Administration-National Heart, Lung, and Blood Institute Study Group for Cooperative Studies on Antihypertensive Therapy: mild hypertension (Perry HM, Jr). Treatment of mild hypertension: preliminary results of a two-year feasibility trial. Circ Res 1977; 40 (suppl 1): 180-87.

44 Barraclough M, Joys MD, MacGregor GA, et al. Control of moderately raised blood pressure: report of a co-operative randomized controlled trial. BMF 1973; 3: 434-36.

45 Veterans Administration Cooperative Study Group on Antihypertensive Agents. Effects of treatment on morbidity in hypertension II: results in patients with diastolic blood pressure averaging 90 through $114 \mathrm{~mm} \mathrm{Hg.} \mathrm{FAMA} \mathrm{1970;} \mathrm{213:}$ $1143-52$
46 Wolff FW, Lindeman RD. Effects of treatment in hypertension: results of a controlled study. F Chron Dis 1966;

19: $227-40$.

47 Carter AB. Hypotensive therapy in stroke survivors. Lancet 1970; 1: $485-89$.

48 Kuramoto K, Matsushita S, Kuwajima I, Murakami M. Prospective study on the treatment of mild hypertension in the aged. Fpn Heart f 1981; 22: 75-85.

49 Hypertension Detection and Follow-up Program Cooperative Group. Five-year findings of the Hypertension Detection and Follow-up Program I: reduction in mortality of persons with high blood pressure, including mild hypertension. fAMA 1979; 242: 2562-71.

50 The IPPPSH Collaborative Group. Cardiovascular risk and risk factors in a randomized trial of treatment based on the beta-blocker oxprenolol: the International Primary Prevention Study in Hypertension (IPPPSH). F Hypertens 1985; 3: 379-92.

51 Wilhelmsen L, Berglund G, Elmfeldt D, et al. Beta-blockers versus diuretics in hypertensive men: main results from the HAPPHY trial. F Hypertens 1987; 5: 561-72.

52 Wikstrand J, Westergren G, Berglund G, et al. Antihypertensive treatment with metoprolol or hydrochlorothiazide in patients aged 60 to 75 years. Report from a double-blind international multicenter study. $7 A M A$ 1986; 255: 1304-10.

53 Estacio RO, Jeffers BW, Hiatt WR, Biggerstaff SL, Gifford N, Schrier RW. The effect of nisoldipine as compared with enalapril on cardiovascular outcomes in patients with non-insulindependent diabetes and hypertension. N Engl f Med 1998; 338: 645-52.

54 Tatti P, Pahor M, Byington RB, et al. Outcome results of the Fosinopril versus Amlodipine Cardiovascular Events Randomized Trial (FACET) in patients with hypertension and NIDDM. Diabet Care 1998; 21: 597-603.

55 European Working Party on High Blood Pressure in the Elderly (EWPHE). An international trial of antihypertensive therapy in elderly patients. Objectives, protocol and organization. Arch Intern Pharmacodyn Thér 1985; 275: 300-34.

56 Curb JD, Pressel SL, Cutler JA, et al. Effect of diuretic-based antihypertensive treatment on cardiovascular disease risk in older diabetic patients with isolated systolic hypertension. FAMA 1996; 276: $1886-92$.

57 Hansson L, Hedner T, Lindholm L, et al. The Captopril Prevention Project (CAPPP) in hypertension-baseline data and current status. Blood Press 1997; 6: 365-67.

58 Davis BR, Cutler JA, Gordon DJ, et al. Rationale and design for the Antihypertensive and Lipid Lowering Treatment to Prevent Heart Attack Trial (ALLHAT). Am f Hypertens 1996; 9: 342-60.

59 Tuomilehto J, Rastenyte D, Birkenhäger WH, et al. Effects of calcium-channel blockade in older patients with diabetes and systolic hypertension. $N$ Engl F Med 1999; 340: 677-84.

60 Staessen JA, Thijs L, Birkenhäger WH, Bulpitt CJ, Fagard R, on behalf of the Syst-Eur Investigators. Update on the Systolic Hypertension in Europe (Syst-Eur) Trial. Hypertension 1999; 33: 1476-77.

61 Wang JG, Staessen JA, Gong L, Liu L, for the Systolic Hypertension in China (Syst-China) Collaborative Group. Chinese trial on isolated systolic hypertension in the elderly. Arch Intern Med 2000; 160: 211-20.

62 Heart Outcomes Prevention Evaluation Study Investigators. Effects of ramipril on cardiovascular and microvascular outcomes in people with diabetes mellitus: results of the HOPE study and MICRO-HOPE substudy. Lancet 2000; 355: 253-59.

63 Agabiti Rosei E, Dal Palù C, Leonetti G, et al. Clinical results of the Verapamil in Hypertension and Atherosclerosis Study. f Hypertens 1997; 15: 1337-44.

64 Davies MJ. Reactive oxygen species, metallo-proteinases, and plaque stability. Circulation 1998; 97: 2382-83.

65 Garg R, Yusuf S, for the Collaborative Group on ACE Inhibitors Trials. Overview of randomized trials of angiotensin-converting enzyme inhibitors on mortality and morbidity in patients with heart failure. $\mathscr{F} A M A$ 1995; 275: 1450-56.

66 Flather MD, Yusuf S, Køber L, et al. Long-term ACE-inhibitor therapy in patients with heart failure or left-ventricular dysfunction: a systematic overview of data from individual patients. Lancet 2000; 355: 1575-81.

67 Staessen JA, Birkenhäger WH, Fagard RH. Dihydropyridine calcium-channel blockers for the treatment of hypertensive patients. Eur Heart f 2000; 21: 2-7. 
68 PROGRESS Collaborative Group. Randomised trial of a perindopril-based blood-pressure-lowering regimen among 6105 individuals with previous stroke or transient ischaemic attack. Lancet 2001; 358: 1033-41.

69 Staessen JA, Wang JG: Blood pressure lowering for the secondary prevention of stroke. Lancet 2001; 358: 1026-27.

\section{Appendix}

ABCD (Appropriate Blood Pressure Control in Diabetes trial); $;^{53}$ ALLHAT (Antihypertensive and Lipid-Lowering Treatment to Prevent Heart Attack Trial); $;^{10,58}$ ATMH (Australian Trial in Mild Hypertension); ${ }^{35}$ CAPPP (Captopril Prevention Project); $;{ }^{4,57}$ EWPHE (trial conducted by the European Working Party on High Blood Pressure in the Elderly); ${ }^{30,55}$ HEP (trial of hypertension in elderly patients in primary care) $;^{28} \mathrm{HDFP}$ (Hypertension Detection and Follow-Up Program); ${ }^{49}$ HOPE (Heart Outcomes Prevention Evaluation Study); ${ }^{7,62}$ HOT (Hypertension Optimal Treatment trial); ${ }^{26}$ HOT $\mathrm{M}$ vs $\mathrm{H}$ (Hypertension Optimal Treatment trial-85 vs $90 \mathrm{~mm}$ $\mathrm{Hg}$ as target diastolic pressure) ${ }^{26} \mathrm{HOT} \mathrm{L}$ vs $\mathrm{H}$ (Hypertension Optimal Treatment trial -80 vs $90 \mathrm{~mm} \mathrm{Hg}$ as target diastolic pressure) ${ }^{26}$ HSCS (Hypertension-Stroke Cooperative Study); ${ }^{36}$ INSIGHT (International Nifedipine GITS Study-Intervention as a Goal in Hypertensive Treatment); ${ }^{8}$ MIDAS (Multicenter Isradipine Diuretic Atherosclerosis Study) $;^{3}$ MIDAS/NICS/VHAS (combined results of MIDAS, ${ }^{3}$ NICS, ${ }^{5}$ and VHAS $^{63}$ ); MRC1 (Medical Research
Council trial of treatment of mild hypertension); ${ }^{33}$ MRC2 (Medical Research Council trial of treatment of hypertension in older adults); $;^{32}$ NORDIL (Nordic Diltiazem Study); ${ }^{9}$ NICS (National Intervention Cooperative Study in Elderly Hypertensives); ${ }^{5}$ OSLO (Oslo Study on the Treatment of Mild Hypertension); ${ }^{29}$ PART2 (Prevention of Atherosclerosis with Ramipril Trial); ${ }^{12}$ PART2/SCAT (combined results of PART2 ${ }^{12}$ and SCAT ${ }^{15}$ ); RCT70-80 (combined results of 4 smaller trials published from 1970 through 1980, including HSCS, ${ }^{36}$ OSLO ${ }^{29}$ USPHS, ${ }^{37}$ and VACS ${ }^{38}$ ); SCAT (Simvastatin/Enalapril Coronary Atherosclerosis Trial); $;^{15}$ SHEP (Systolic Hypertension in the Elderly Program); ${ }^{39,56}$ STONE (Shanghai Trial of Nifedipine in the Elderly); ${ }^{34}$ STOP1 (Swedish Trial in Old Patients with hypertension); ${ }^{31}$ STOP2 (Swedish Trial in Old Patients with hypertension-2); ${ }^{6}$ STOP2/ACEIs (angiotensin-converting enzyme inhibitor arm of STOP2); ${ }^{6}$ STOP2/CCBs (calcium-channel blocker arm of STOP2); ${ }^{6}$ Syst-China (Systolic Hypertension in China trial) $;^{41,61}$ Syst-Eur (Systolic Hypertension in Europe trial); ${ }^{40,59,60}$ UKPDS (UKPDS Hypertension in Diabetes Study); ;16,27 UKPDS C vs A (UKPDS Hypertension in Diabetes Study-captopril vs atenolol); ${ }^{16}$ UKPDS L vs $\mathrm{H}$ (UKPDS Hypertension in Diabetes Study-low vs high on-treatment blood pressure); ${ }^{27}$ USPHS (United States Public Health Service Hospitals Cooperative Study); $;^{37}$ VACS (Veterans Administration Cooperative Study in patients with diastolic blood pressure averaging $90-114 \mathrm{~mm} \mathrm{Hg}$ ) ${ }^{38}$ VHAS (Verapamil in Hypertension and Atherosclerosis Study). ${ }^{63}$ 